\title{
Capabilities of Satellite-Based Precipitation to Estimate the Spatiotemporal Variation of Flood/Drought Class in Poyang Lake Basin
}

\author{
Xianghu Li, ${ }^{1}$ Qi Zhang, ${ }^{1}$ and Xuchun Ye ${ }^{2}$ \\ ${ }^{1}$ State Key Laboratory of Lake Science and Environment, Nanjing Institute of Geography and Limnology, \\ Chinese Academy of Sciences, 73 East Beijing Road, Nanjing 210008, China \\ ${ }^{2}$ School of Geographical Sciences, Southwest University, Chongqing 400715, China \\ Correspondence should be addressed to Xianghu Li; 1xh8010@163.com
}

Received 16 June 2013; Revised 18 November 2013; Accepted 26 November 2013

Academic Editor: Luis Gimeno

Copyright @ 2013 Xianghu Li et al. This is an open access article distributed under the Creative Commons Attribution License, which permits unrestricted use, distribution, and reproduction in any medium, provided the original work is properly cited.

\begin{abstract}
Poyang Lake basin is one of the most frequently affected areas by a variety of flood or drought events in China. Satellite-based precipitation data have greatly improved their temporal and spatial resolution in recent years, but the short length of records limited their applications in some fields. This paper compared and evaluated the creditability of using a short period data series to estimate the statistics characteristics of long period data series and investigated the usefulness of TRMM rainfall data for monitoring the temporal and spatial distribution of flood/drought classes by the $Z$ index method in Poyang Lake basin. The results show that (1) the 1998-2010 data series are sufficiently robust to depict the statistics characteristics of long period data; (2) the intraannual distribution and interannual variability of flood/drought classes based on TRMM rainfall data matched well with the results from rain gauges data; (3) the spatial agreement between TRMM and interpolated gauges rainfall varied with the precipitation characteristics; and (4) TRMM rainfall data described the similar spatial pattern of flood/drought classes with the interpolated gauges rainfall. In conclusion, it is suitable and credible for flood/drought classes evaluation based on the TRMM rainfall data in Poyang Lake basin.
\end{abstract}

\section{Introduction}

Poyang Lake, the largest freshwater lake in China, is located in the middle and lower reaches of the Yangtze River and directly exchanges water and interacts with the Yangtze River [1]. The discharges from Poyang Lake through a channel in its northern part into the Yangtze River are higher than the total runoff from the Yellow River, Haihe River, and Huaihe River and play an important role in water security and ecosystem security for the middle and lower reaches of the Yangtze River [2]. In recent decades, the lake and its surrounding catchments have suffered from frequent droughts and floods, especially in 1990s and 2000s [3-5]. These severe drought and flood events have caused severe economic losses and serious damages to towns and farms or even human death $[6,7]$ and have raised concerns for the lake ecology and local water resources management [8]. Therefore, it is necessary to monitor the development and spatial distribution of floods and droughts in Poyang Lake basin for prevention and mitigation of flood/drought disaster.

Satellite can continuously monitor the precipitation over a large area and receive the rainfall data in near real time. Recent development in global and regional satellite-based precipitation products has greatly improved their application in a broad fields, such as, hydrological processes modeling [9-11], precipitation distribution characteristics analysis [12], weather processes analysis [13], latent heat analysis [14], and soil erosion calculation [15]. This is mainly due to the increased temporal and spatial resolution of satellite-based precipitation data and also due to improved accuracy resulting from new methods to merge various data sources such as radar, microwave, and thermal infrared remote sensing [10, 16, 17]. Especially, the Tropical Rainfall Measuring Mission (TRMM) satellite precipitation data, with higher quality 
than other satellite-based precipitation products, have been recommended to apply in scientific researches [18] and are also expected to offer an alternative to ground-based rainfall estimates in the present and the foreseeable future [19].

Recently, several attempts have been made to monitor the drought or flood using TRMM rainfall data. For example, Du et al. [20] adopted a synthesized drought index integrating MODIS and TRMM data to monitor the droughts in Shandong Province, China. Vernimmen et al. [21] evaluated and corrected the bias of satellite rainfall data for drought monitoring in Indonesia. Zeng et al. [22] also evaluated the application of TRMM rainfall in drought monitoring in the Lancang River basin. Naumann et al. [23] investigated the uncertainties of monitoring drought conditions using TRMM data in Africa. However, the Poyang Lake basin has received far less attention and the similar researches were seldom, which did not satisfy the demands of floods protection and regulation or droughts mitigation and ensuring the water safety in areas around the lake. On the other hand, the effects of short period TRMM records on estimation of statistics characteristics and the cumulative probability function are still unclear. AghaKouchak and Nakhjiri [24] has combined the TRMM data with long-term Global Precipitation Climatology Project (GPCP) observations to avoid the limitation of short records of TRMM data for drought monitoring and analysis, but other previous studies did not take these limitations into account.

Therefore, the objectives of the study are designed to (1) compare the statistics characteristics between a short period and a long period data series and determine the creditability of using the 1998-2010 data series to estimate the cumulative probability function and (2) investigate the usefulness of TRMM rainfall data for monitoring the temporal and spatial distribution of flood/drought classes by the $Z$ index method in Poyang Lake basin. The rest of this paper is organized as follows. In the next section details of the study area, climate, and data as well as methods used in the study are described with the help of cited references. In Section 3, major results are presented and discussed, and Section 4 summarizes the conclusions.

\section{Study Area and Methods}

2.1. Study Area and Data. The Poyang Lake, connected to the Yangtze River, lies on the northern border of the Jiangxi Province, China, and receives water flows mainly from five rivers, Xiushui River, Ganjiang River, Fuhe River, Xinjiang River, and Raohe River, and discharges into the Yangtze River (Figure 1). The total drainage area of the water systems is $16.22 \times 10^{4} \mathrm{~km}^{2}$, accounting for $9 \%$ of the drainage area of the Yangtze River basin. The topography in basin varies from highly mountainous and hilly areas (maximum elevation of about $2200 \mathrm{~m}$ above sea level) to alluvial plains in the lower reaches of the primary watercourses. Headwater of these rivers is located in boundaries of the east, south, and west of the Jiangxi Province that is surrounded by high mountains. The wide alluvial plains surrounding Poyang Lake and the broad alluvial valleys of the tributary streams are

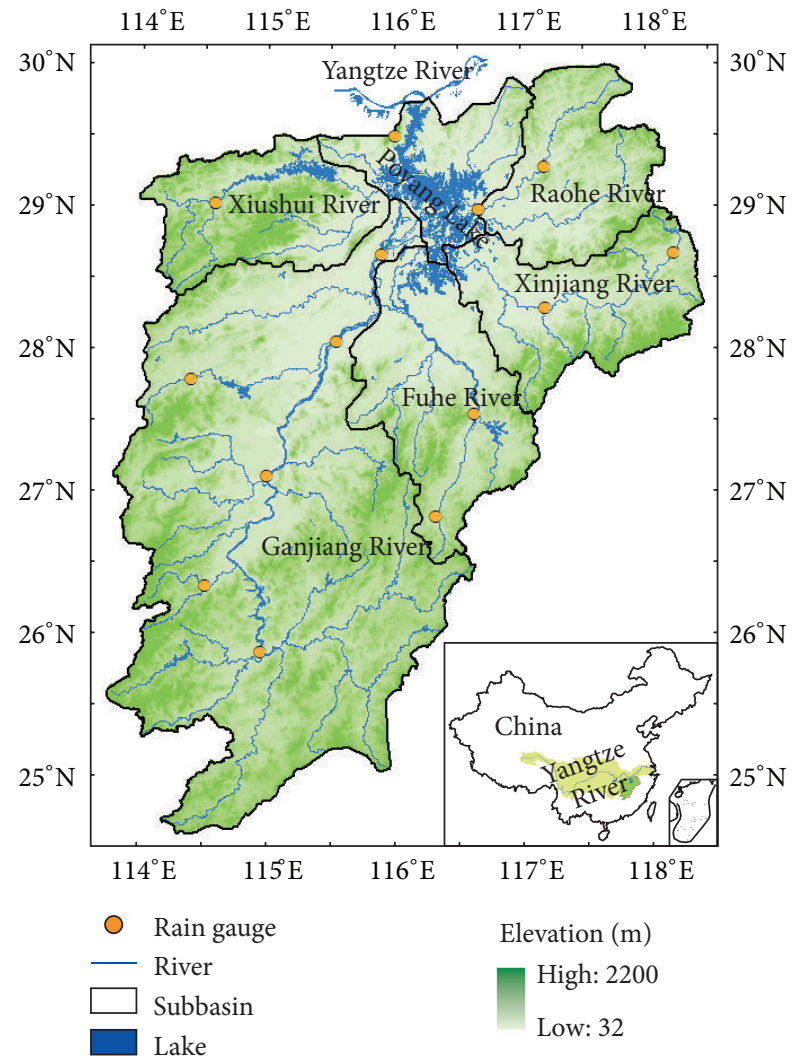

FIgURE 1: Location of Poyang Lake basin and the distribution of rain gauges.

important rice growing regions in Jiangxi Province as well as in China [25]. Poyang Lake basin has a subtropical wet climate characterized with a mean annual precipitation of $1680 \mathrm{~mm}$ for the period of 1960-2007 and annual mean temperature of $17.5^{\circ} \mathrm{C}$. Annual precipitation shows a wet and a dry season and a short transition period in between. In response to annual cycle of precipitation, about $59.1 \%$ of the annual discharge arrive from March to June, but only 13.7\% arrive from October to next January. In normal years, the Poyang Lake can expand to a large water surface of $4000 \mathrm{~km}^{2}$ with a volume of $320 \times 10^{8} \mathrm{~m}^{3}$ in the wet season but shrinks to little more than a river during the dry season [26].

Satellite-based rainfall data used in this study are TRMM 3B42-V6 daily data at $0.25^{\circ} \times 0.25^{\circ}$ grid resolution from January 1, 1998, to December 31, 2010, and the monthly TRMM data are aggregated from the daily rainfall data. The daily gauges rainfall data for 14 national meteorological stations in the Poyang Lake basin during the period 19702010 are collected from National Meteorological Information Center of China, which are used to compare the statistics characteristics between a short period and a long period data series and determine the creditability of using the 1998-2010 data series to estimate the cumulative probability function. The distribution of rain gauges in the basin is shown in Figure 1. These data have been widely used for different studies previously and the quality has been approved to be 

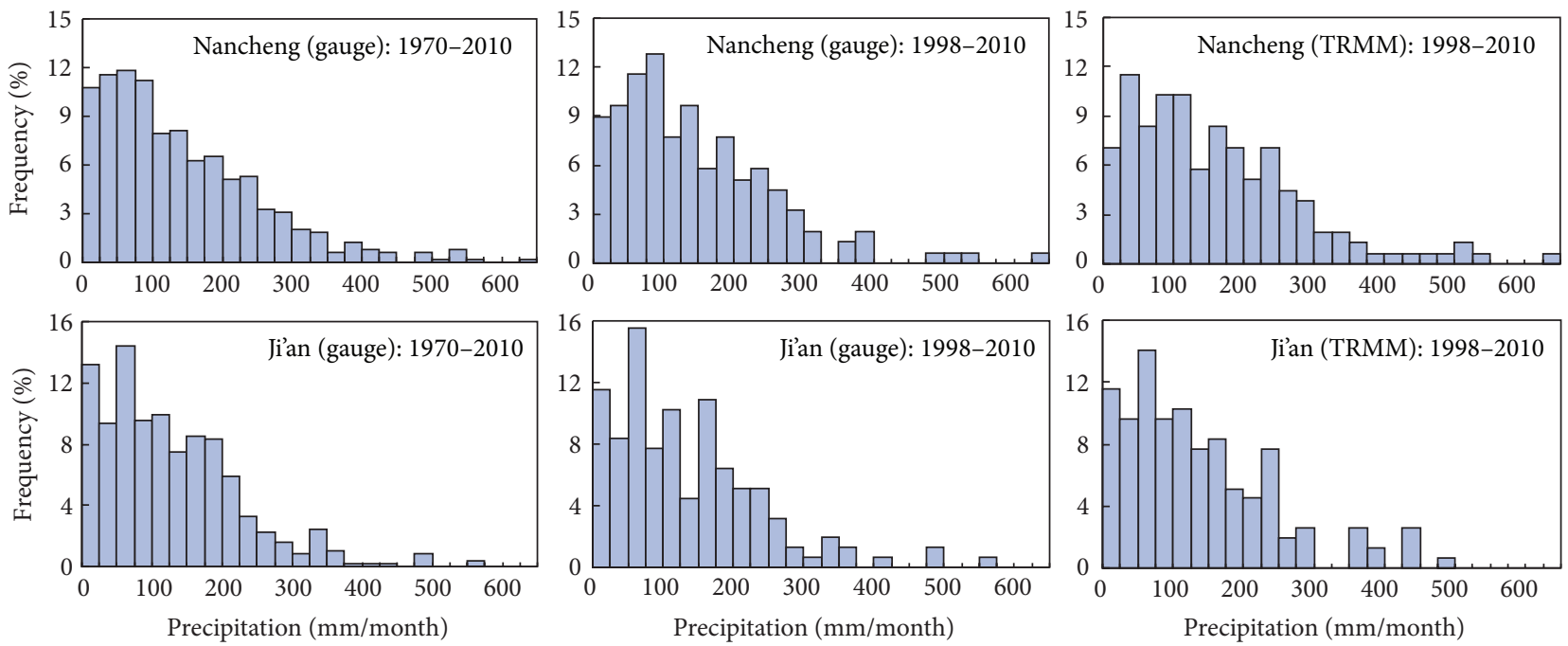

FIgURE 2: Comparison of histogram of frequencies for the long and short period data at Nancheng and Jian station.
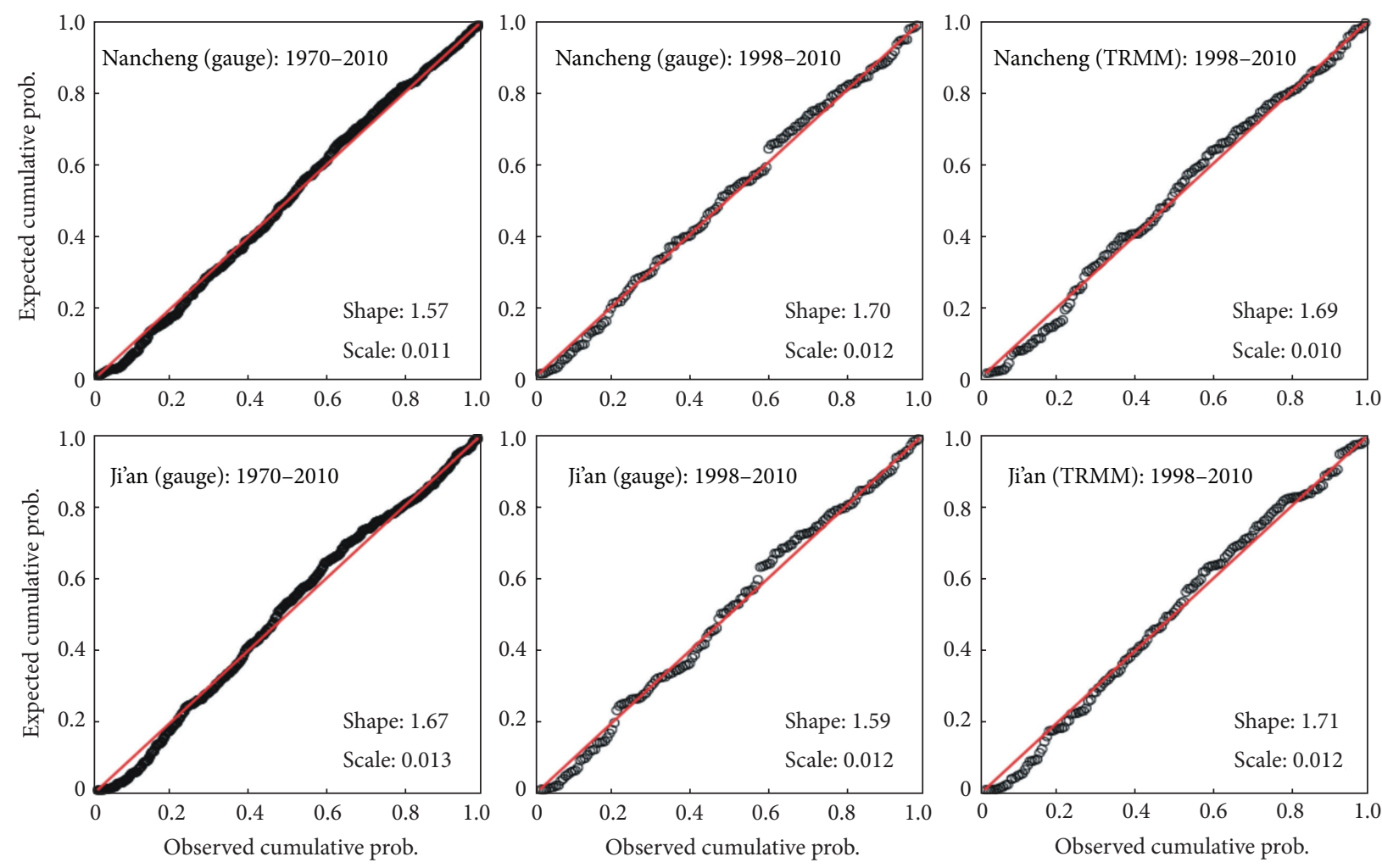

Figure 3: Comparison of Gamma P-P plots for the long and short period data at Nancheng and Jian station.

reliable $[1,2,27]$. We also examined the relation between elevation and rainfall to reflect the difference in mountainous region and in lowlands, but there is no clear evidence that the rainfall changed with elevation in the study region. So, the daily gauges rainfall data are directly interpolated to grid $\left(0.25^{\circ} \times 0.25^{\circ}\right)$ for the whole basin with the method of Inverse Distance Weighted (IDW) technique.
2.2. Methods. The $Z$ index is an extensively used drought index in China, due to its robustness and convenience to calculate, and has been used at monthly time scale as the principal index to monitor drought and flood conditions in different regions of China $[28,29]$. Daley believed that the precipitation over a period usually obeys the Gamma distribution, and the probability density function can be 


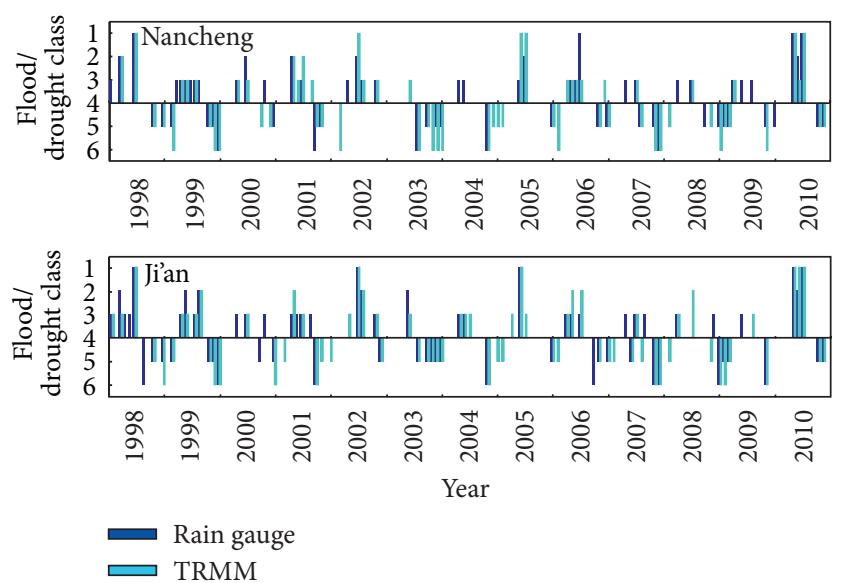

FIgURE 4: Comparison of flood/drought classbased on $Z$ index using TRMM and rain gauges data.
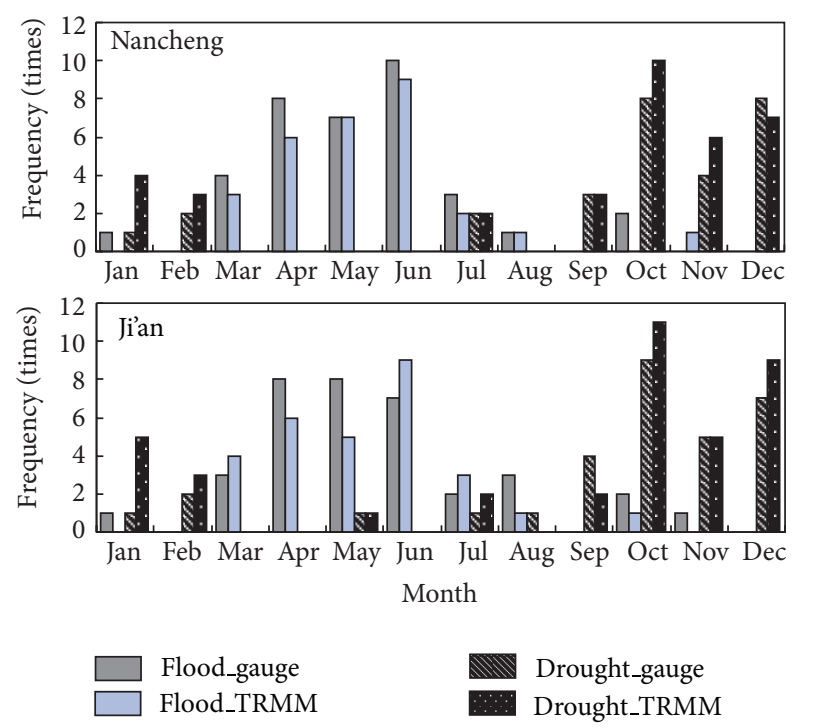

FIGURE 5: Intra-annual distribution of flood/drought frequency based on TRMM and rain gauges data.

converted to a Normal distribution through the following conversion function [30]:

$$
Z_{i}=\frac{6}{C_{s}}\left(\frac{C_{s}}{2} \varphi_{i}+1\right)^{1 / 3}-\frac{6}{C_{s}}+\frac{C_{s}}{6}
$$

where $Z_{i}$ is the $Z$ index for the precipitation in the $i$ th month, $C_{s}$ is coefficient of skewness, and $\varphi_{i}$ is the standardized monthly precipitation. Both $C_{s}$ and $\varphi_{i}$ can be calculated from the monthly precipitation of stations;

$$
\begin{gathered}
C_{s}=\frac{\sum_{i=1}^{n}\left(P_{i}-\bar{P}\right)^{3}}{n \sigma_{3}}, \\
\varphi_{i}=\frac{P_{i}-\bar{P}}{\sigma},
\end{gathered}
$$

TABLE 1: Flood and drought classification based on the $Z$ index values.

\begin{tabular}{lcc}
\hline Class & $Z$ value & Type \\
\hline 1 & $Z>1.96$ & Severe flood \\
2 & $1.44<Z \leq 1.96$ & Moderate flood \\
3 & $0.84<Z \leq 1.44$ & Slight flood \\
4 & $-0.84 \leq Z \leq 0.84$ & Normal \\
5 & $-1.44 \leq Z<-0.84$ & Slight drought \\
6 & $-1.96 \leq Z<-1.44$ & Moderate drought \\
7 & $Z<-1.96$ & Severe drought \\
\hline
\end{tabular}

where $P_{i}$ is the precipitation in the $i$ th month, $n$ is the total month, and $\sigma$ and $\bar{P}$ are the standard error and mean of precipitation in all month.

Each TRMM grid $\left(0.25^{\circ} \times 0.25^{\circ}\right)$ is regarded as a ground rain station in the study, same as the treatments of $\mathrm{Li}$ et al. [31], and the $Z$ index is computed for each grid. Subsequently, the different flood and drought classes are defined based on the $Z$ index, including the severe flood, moderate flood, slight flood, normal, slight drought, moderate drought, and severe drought [31]. The criterion of classification and $Z$ index value range for each class of flood/drought was shown in Table 1.

\section{Results and Discussions}

3.1. Suitability of TRMM Rainfall for Statistics Characteristics of Long Period Data Series. Due to the TRMM precipitation data are only available from January 1998 and its short time records are a main limitation for fitting the data to a probability distribution function, we firstly analyzed the consistency of several statistical indices such as mean, maximal, minimal, and standard deviation between a long (1970-2010) and a short period (1998-2010) rain gauges data as well as TRMM data. Considering the relative location of rain gauges in the grid and the spatial distribution in the basin, the comparison was made for two selected gauging station (namely, Nancheng and Jian) and their nearest grid, respectively, and the results were shown in Table 2. It is seen that the average monthly gauge rainfall for long period and short period was $142.4 \mathrm{~mm}$ and $145.8 \mathrm{~mm}$ at Nancheng station and $127.4 \mathrm{~mm}$ and $130.9 \mathrm{~mm}$ at Jian station. The maximal as well as minimal rainfalls were equivalent for two data sets at Nancheng and Jian station. The similar situations were observed further in the comparison of standard deviation. The short period gauge data can present the characteristics of long period records. However, the TRMM rainfall data did not accurately capture the characteristics of gauges rainfall at both Nancheng and Jian grid, especially for estimating the maximal rainfall with a large error.

Figure 2 shows the histogram of frequencies for the long and short period data at Nancheng and Jian station, respectively. It is seen that the distribution of occurrence frequency was similar between using 1970-2010 gauging data set, 1998-2010 gauging data set and TRMM data both at Nancheng and Jian station. Figure 2 indicated that there are no essential differences between the long and short period 

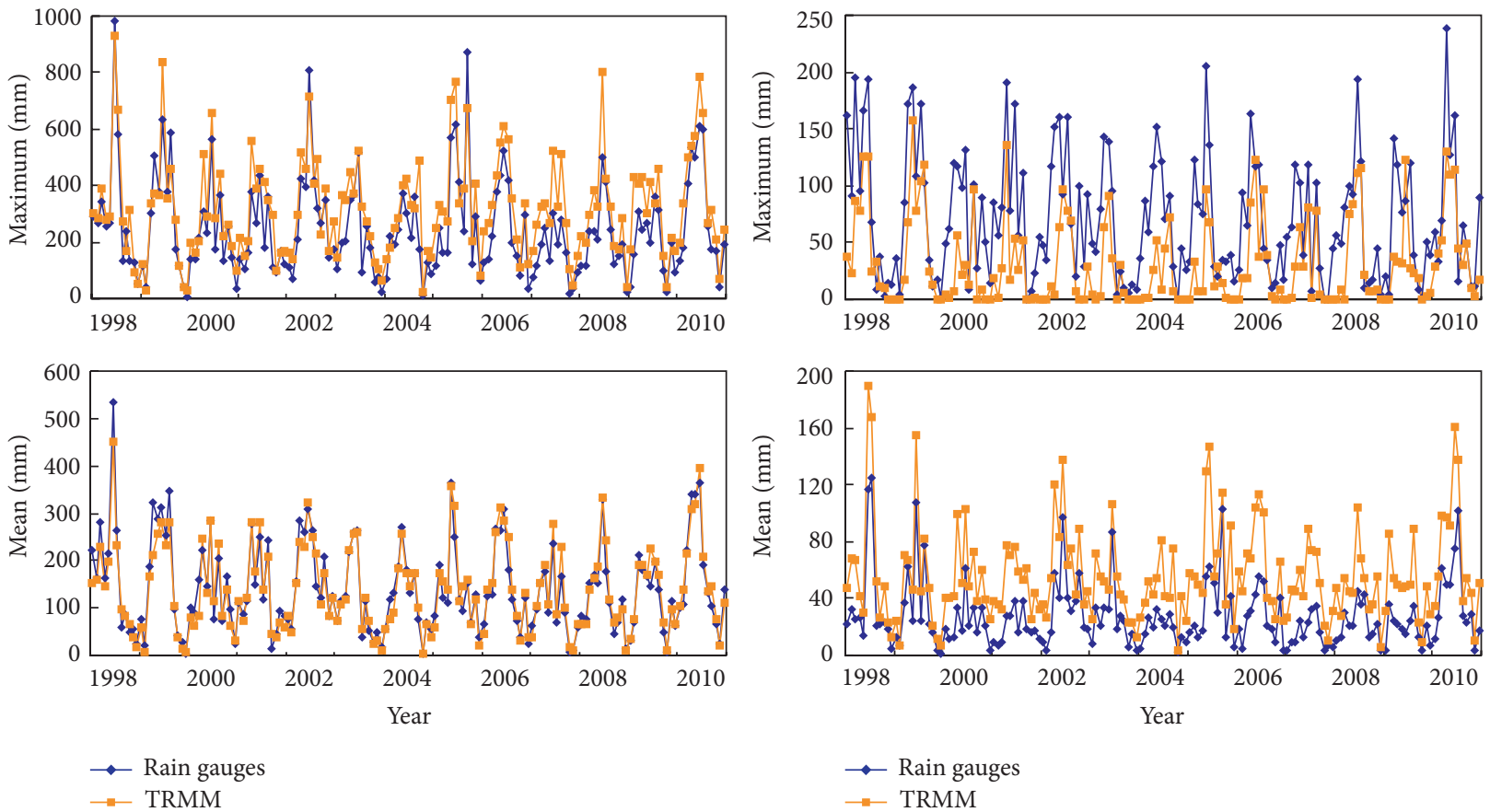

FIGURE 6: Comparison of maximum, minimum, mean and standard deviation between TRMM and interpolated gauges rainfall.

TABLE 2: Comparison of statistical indices between short and long period data series.

\begin{tabular}{lccccc}
\hline Station & Data set & Mean $(\mathrm{mm} / \mathrm{month})$ & Max. $(\mathrm{mm} / \mathrm{month})$ & Min. $(\mathrm{mm} / \mathrm{month})$ & 0 \\
\multirow{3}{*}{ Nancheng } & 142.4 & 635.6 & 635.6 & 0 & 113.3 \\
& Gauge 1970-2010 & 145.8 & 715.4 & 0.27 & 111.5 \\
& Gauge 1998-2010 & 161.3 & 574 & 0 & 123.8 \\
\multirow{3}{*}{ Jian } & TRMM 1998-2010 & 127.4 & 563.5 & 0.6 & 98.5 \\
& Gauge 1970-2010 & 130.9 & 480.5 & 0 & 103.3 \\
& Gauge 1998-2010 & 138.9 & TRMM 1998-2010 & &
\end{tabular}

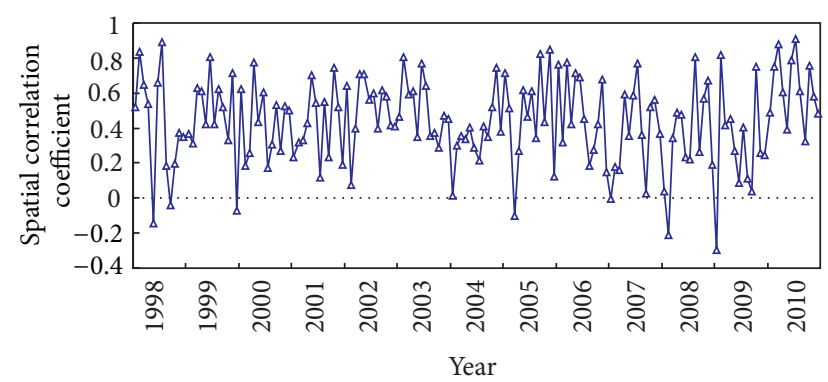

FIGURE 7: Variation of spatial correlation between TRMM and interpolated gauges rainfall.

data for statistics characteristics. Subsequently, the presupposition that the precipitation at a location for a specified time period obey the Gamma distribution was checked by a long and short period data series and TRMM data respectively. Figure 3 shows the Gamma probability-probability (P-P) plot at Nancheng and Jian station. The P-P plot compared the empirical cumulative probability of data set with the theoretical cumulative probability of Gamma distribution. It is seen that the plotted points, both from the long period data set and short period data set, lie on $x=y$ diagonal. The coincident cumulative probability function indicated that the precipitation obeys the Gamma distribution, regardless of using long period, short period records or TRMM data. At the same time, the shape and scale parameters of Gamma distribution estimated from the 1970-2010 data set are 1.57 and 0.011 and 1.70 and 0.012 for the 1998-2010 data set and 1.69 and 0.01 for TRMM data at Nancheng station. The similar parameter values were also gained using different data set at Jian station. All above analysis indicated that the short period (1998-2010) data are sufficiently robust to depict the statistics characteristics of long period data series.

3.2. Temporal Variation of Flood/Drought Classes Based on TRMM Rainfall. The $Z$ index values are computed for each grid $\left(0.25^{\circ} \times 0.25^{\circ}\right)$ in Poyang Lake basin using the monthly TRMM rainfall data during January 1998 to December 2010. At the same time, as a comparison, the rain gauges data from 14 national meteorological stations in the basin are also used to calculate the $Z$ index. A positive $Z$ value indicates an above 

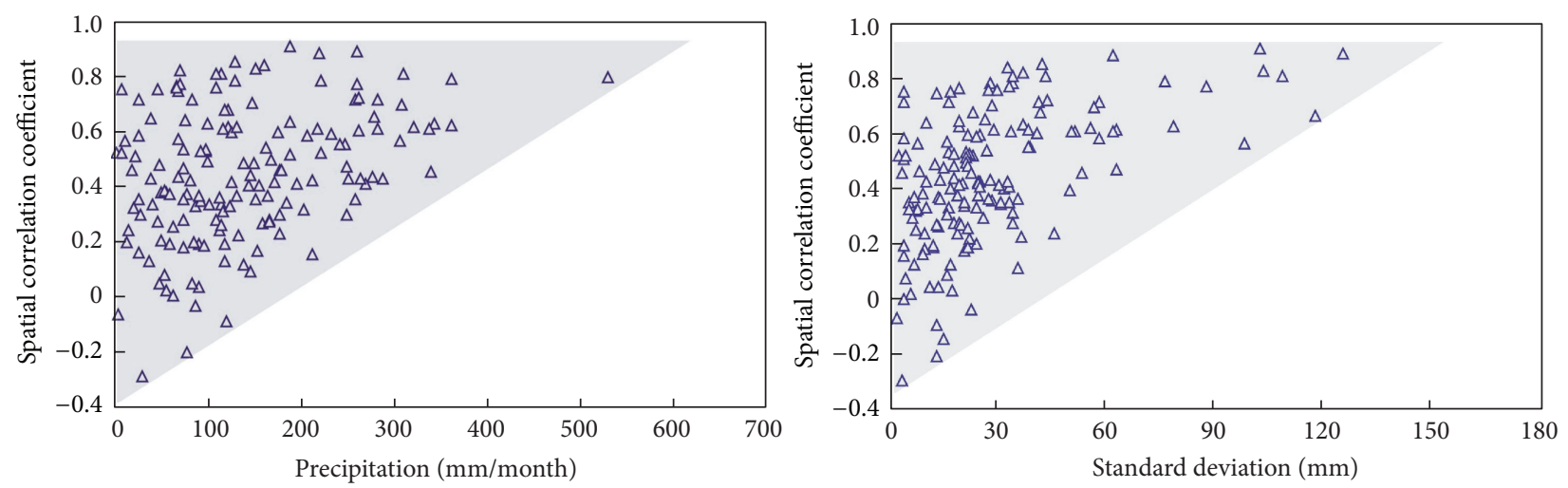

FIGURE 8: Scatter plots of spatial agreement versus average monthly rainfall and standard deviation.

average precipitation accumulation over a period of time (i.e., 1 month), whereas a negative $Z$ indicates a dry with an average precipitation accumulation below the climatological mean. A $Z$ value near zero refers to precipitation accumulation near the climatological mean [24]. The flood/drought classes are determined according to the $Z$ index value ranges as shown in Table 1. Figure 4 shows the comparison of flood/drought class determined using rain gauges data and TRMM data. It is seen that the flood/drought classes based on monthly TRMM rainfall data oscillate around four (normal), and their interannual variability generally match well with the results from rain gauge data, although it misestimated the flood or drought class in several months. From the results of Figure 4, we believed that it is feasible to use monthly TRMM rainfall data to determine the variation of flood/drought classes in Poyang Lake basin.

In order to further analyze the temporal distribution of flood/drought events in intra-annual, the flood/drought classes are reclassified as three types; for example, the severe flood, moderate flood, and slight flood are all classified into flood, and the severe drought, moderate drought, and slight drought are all classified into drought. The flood/drought frequency based on TRMM data and rain gauges data during 1998-2010 at Nancheng and jian is shown in Figure 5. It is seen that the statistical results from TRMM data are close to that from rain gauges data. Moreover, flood events mainly occurred between April and June (occupying about 60\% of the total times), which are also the main wet season for the Poyang Lake basin and the heavy rainfall usually resulted in the flood disaster, while drought events mainly happened during October to the next January. The temporal distribution of flood/drought events in intra-annual based on TRMM data is consistent with the intra-annual variation of observed rainfall in Poyang Lake basin, which further indicated that it is fairly reliable to apply TRMM rainfall data to regional flood/drought analysis.

3.3. Spatial Agreement between TRMM and Rain Gauges Rainfall Data. The TRMM data are available over a large area and can reflect the spatial development of flood/drought in real time. So, the presented research is also extended to examine and compare the spatial accuracy of flood/drought events. The monthly rain gauges data are directly interpolated to $0.25^{\circ} \times 0.25^{\circ}$ grid (same with the resolution of TRMM data) by the IDW technique for the whole basin. Figure 6 shows the comparison of maximum, minimum, mean, and standard deviation between TRMM rainfall and interpolated gauges rainfall. It is seen that both data sets reflected the same variation processes in terms of maximum and mean rainfall. Although a slight difference was exhibited in comparison of minimum and standard deviation, the changing trends based on TRMM data are consistent with that based on rain gauges data.

Figure 7 shows the variation of spatial correlation between TRMM and interpolated gauges rainfall. It is seen that the spatial correlation coefficient oscillates around 0.5, and their spatial agreement varied with the precipitation characteristics in different month. So, the study further investigated the relationship of spatial agreement with average monthly rainfall and standard deviation and the results are shown in Figure 8. It is seen that the points lay in a triangle area. On the one hand, the spatial correlation coefficient lay in a wide range when the rainfall amount and standard deviation are small; on the other hand, the spatial agreement becomes higher with the increasing of rainfall amount and unevenness in spatial distribution. This may be resulted from the sparsity of rain gauges as well as the weakness of the interpolation technique, which did not accurately reflected the spatial characteristics of monthly rainfall when the rainfall amount is small.

\subsection{Spatial Distribution of Flood/Drought Classes Based on} TRMM Rainfall. Figure 9 shows the spatial distribution of flood/drought classes based on the interpolated gauges rainfall and TRMM rainfall data, respectively. The comparison was made in April 2010 (with average rainfall of $340 \mathrm{~mm}$ and spatial correlation coefficient of 0.61) and July 2003 (with average rainfall of $38 \mathrm{~mm}$ and spatial correlation coefficient of 0.64). In April 2010, the heavy rainfall occurred in the middle area of Poyang Lake basin, traversing from east to the west parts with the monthly rainfall as high as $530 \mathrm{~mm}$, while the lowest one was observed in the southern and northern parts (about $230 \mathrm{~mm}$ ). Correspondingly, the $Z$ index showed a high flood risk in the middle parts of the basin 

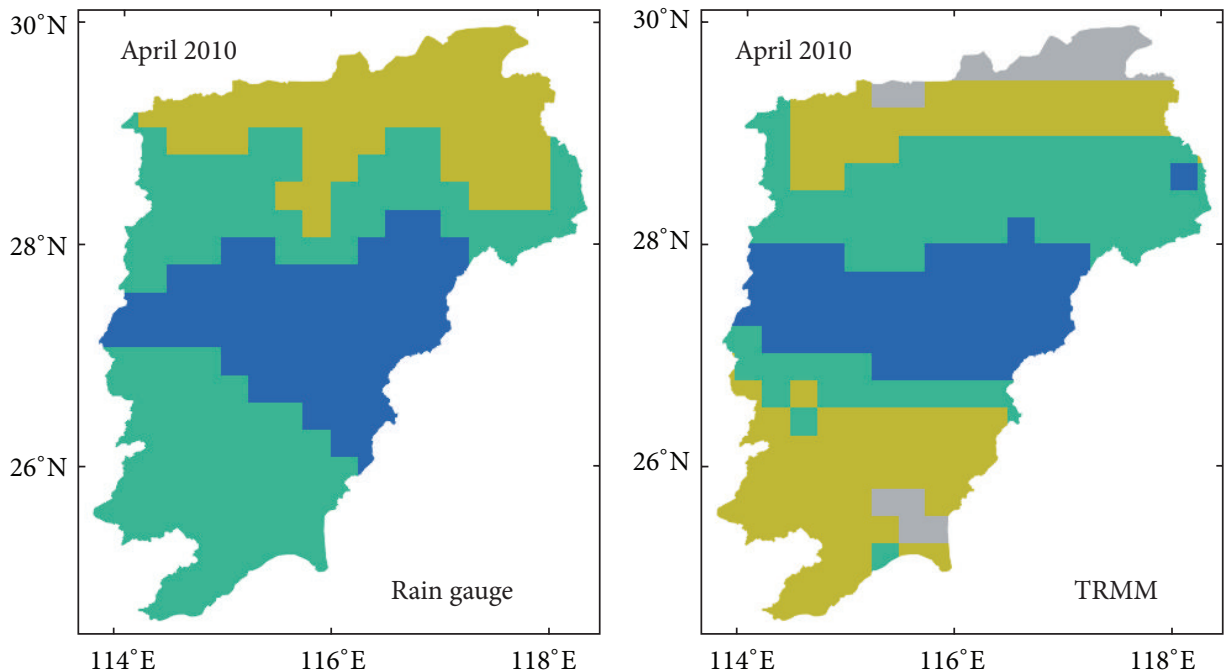

Flood/drought class
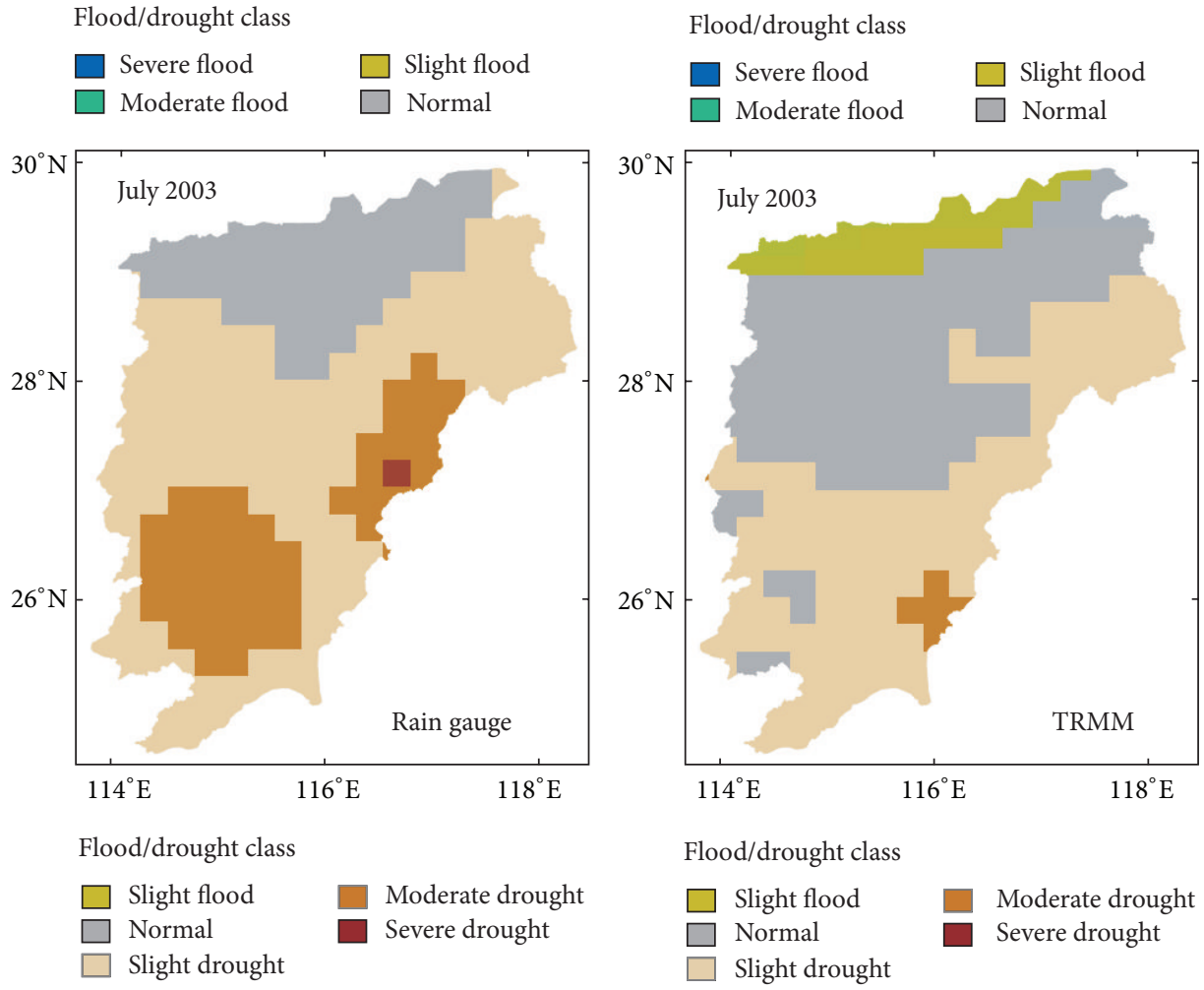

FIGURE 9: Spatial distribution of flood/drought classes based on the interpolated gauges rainfall and TRMM data in April 2010 and July 2003.

than that in southern and northern. The spatial distribution of flood/drought classes derived from TRMM rainfall data also described the same spatial structures, although the slight flood class covered a larger area in southern than that from the interpolated gauges rainfall. Also in July 2003, the similar spatial pattern of flood/drought classes was presented by the interpolated gauges rainfall and TRMM rainfall data, respectively; that is, the slight and moderate drought occurred in the south but normal in the northwest based on both the interpolated gauges rainfall and TRMM rainfall data. Figure 9 suggested that the spatial distribution of flood/drought classes based on TRMM rainfall data agreed with that of interpolated gauges rainfall, and TRMM rainfall data can be used for monitoring the spatial distribution of flood/drought in Poyang Lake basin.

\section{Conclusions}

This paper compared and evaluated the statistics characteristics between a short period and a long period data series and investigated the usefulness of satellite-based rainfall data (i.e., TRMM) for monitoring the temporal and spatial distribution of flood/drought classes by the $Z$ index method in Poyang Lake basin. The results revealed that (1) the 1998-2010 data 
series have the coincident cumulative probability function with the 1970-2010 data series and are sufficiently robust to depict the statistics characteristics of long period data; (2) the flood/drought classes based on TRMM rainfall data oscillate around four (normal), and their intra-annual distribution and interannual variability generally match well with the results from rain gauge data; (3) the spatial agreement between TRMM and interpolated gauges rainfall varied with the precipitation characteristics in different month, which will become higher with the increasing of rainfall amount and unevenness in spatial distribution; (4) TRMM rainfall data described the similar spatial pattern of flood/drought classes with the interpolated gauges rainfall and can be used for monitoring the spatial distribution of flood/drought in Poyang Lake basin.

It should be pointed out that the further studies and researches are still needed in applying the TRMM rainfall data to monitoring flood/drought in the watershed. It is likely that the results presented in this study cannot fully demonstrated the spatial and temporal distribution characteristics of flood/drought in Poyang Lake basin and also may not completely accorded with the actual flood/drought events. But, TRMM rainfall data have its inherent advantages in depicting the spatial distribution of rainfall in large-scale watersheds than ground rain gauges, the presented study provided a new technique or approach to flood/drought monitoring at the large-scale watersheds.

\section{Conflict of Interests}

The authors declare that there is no conflict of interests regarding the publication of this paper.

\section{Acknowledgments}

This work is jointly funded by the National Basic Research Program of China (973 Program) (2012CB417003), the National Natural Science Foundation of China (41101024), and the Open Research Fund of State Key Laboratory of Simulation and Regulation of Water Cycle in River Basin (China Institute of Water Resources and Hydropower Research) (IWHR-SKL-201111). The authors are grateful to the anonymous reviewers and the editor who helped them improve the quality of original paper.

\section{References}

[1] Q. Hu, S. Feng, H. Guo, G. Chen, and T. Jiang, "Interactions of the Yangtze river flow and hydrologic processes of the Poyang lake, China," Journal of Hydrology, vol. 347, no. 1-2, pp. 90-100, 2007.

[2] H. Guo, Q. Hu, and T. Jiang, "Annual and seasonal streamflow responses to climate and land-cover changes in the Poyang lake basin, China," Journal of Hydrology, vol. 355, no. 1-4, pp. 106122,2008 .

[3] F. Wang, D. Y. Wu, and R. F. Li, "Analysis on flood disaster characteristic in lake Poyang region," Journal of Lake Science, vol. 20, no. 4, pp. 500-506, 2008 (Chinese).
[4] M. X. Yu, Q. F. Li, M. J. Hayes, M. D. Svoboda, and R. R. Heim, "Are droughts becoming more frequent or severe in China based on the standardized precipitation evapotranspiration index: 1951-2010?” International Journal of Climatology, 2013.

[5] Q. Min, J. G. Shi, and D. Min, "Characteristics of sediment into and out of Poyanghu lake from 1956 to 2005," Journal of China Hydrology, vol. 31, no. 1, pp. 54-58, 2011 (Chinese).

[6] Y. Zhao, "Thinking on the flood disaster in the middle reaches of the Yangtze river," Earth Science Frontiers, vol. 7, pp. 87-93, 2000.

[7] S. M. Cai, Y. Du, J. Huang, S. Wu, and H. Xue, "Causes of flooding and water logging in middle reaches of the Yangtze river and construction of decision-making support system for monitoring and evaluation of flooding and water logging hazards," Earth Science, vol. 26, no. 6, pp. 643-647, 2001 (Chinese).

[8] D. Shankman, B. D. Keim, and J. Song, "Flood frequency in China's Poyang lake region: trends and teleconnections," International Journal of Climatology, vol. 26, no. 9, pp. 12551266, 2006.

[9] X. H. Li, Q. Zhang, and C. Y. Xu, "Suitability of the TRMM satellite rainfalls in driving a distributed hydrological model for water balance computations in Xinjiang catchment, Poyang lake basin," Journal of Hydrology, vol. 426-427, pp. 28-38, 2012.

[10] S. Stisen and I. Sandholt, "Evaluation of remote-sensing-based rainfall products through predictive capability in hydrological runoff modelling," Hydrological Processes, vol. 24, no. 7, pp. 879891,2010

[11] L. Samaniego, R. Kumar, and C. Jackisch, "Predictions in a datasparse region using a regionalized grid-based hydrologic model driven by remotely sensed data," Hydrology Research, vol. 42, no. 5, pp. 338-355, 2011.

[12] L. Hu, Y. D. Li, Y. Song, and D. F. Deng, "Seasonal variability in tropical and subtropical convective and stratiform precipitation of the east asian monsoon," Science China Earth Sciences, vol. 54, no. 10, pp. 1595-1603, 2011.

[13] J. Y. Mao and G. X. Wu, "Diurnal variations of summer precipitation over the asian monsoon region as revealed by TRMM satellite data," Science China Earth Sciences, vol. 55, no. 4, pp. 554-566, 2012.

[14] Y. F. Fu, Q. Liu, Y. Zi, S. Feng, Y. Q. Li, and G. S. Liu, "Summer precipitation and latent heating over the tibetan plateau based on TRMM measurements," Plateau and Mountain Meteorology Research, vol. 28, no. 1, pp. 8-18, 2008 (Chinese).

[15] Q. Zhu, X. W. Chen, Q. X. Fan, H. Jin, and J. Li, "A new procedure to estimate the rainfall erosivity factor based on Tropical Rainfall Measuring Mission (TRMM) data," Science China Technological Sciences, vol. 54, no. 9, pp. 2437-2445, 2011.

[16] J. Gottschalck, J. Meng, M. Rodell, and P. Houser, "Analysis of multiple precipitation products and preliminary assessment of their impact on global land data assimilation system land surface states," Journal of Hydrometeorology, vol. 6, no. 5, pp. 573-598, 2005.

[17] Y. D. Tian and C. D. Peters-Lidard, "Systematic anomalies over inland water bodies in satellite-based precipitation estimates," Geophysical Research Letters, vol. 34, no. 14, Article ID L14403, 2007.

[18] G. J. Huffman, R. F. Adler, D. T. Bolvin et al., "The TRMM Multisatellite Precipitation Analysis (TMPA): quasi-global, multiyear, combined-sensor precipitation estimates at fine scales," Journal of Hydrometeorology, vol. 8, no. 1, pp. 38-55, 2007.

[19] T. Sawunyama and D. A. Hughes, "Application of satellitederived rainfall estimates to extend water resource simulation 
modelling in South Africa," Water SA, vol. 34, no. 1, pp. 1-9, 2008.

[20] L. T. Du, Q. J. Tian, T. Yu et al., "A comprehensive drought monitoring method integrating MODIS and TRMM data," International Journal of Applied Earth Observation and Geoinformation, vol. 23, pp. 245-253, 2013.

[21] R. R. E. Vernimmen, A. Hooijer, M. Mamenun, E. Aldrian, and A. I. J. M. Van Dijk, "Evaluation and bias correction of satellite rainfall data for drought monitoring in Indonesia," Hydrology and Earth System Sciences, vol. 16, no. 1, pp. 133-146, 2012.

[22] H. W. Zeng, L. J. Li, and J. Y. Li, "The evaluation of TRMM Multisatellite Precipitation Analysis (TMPA) in drought monitoring in the Lancang river basin," Journal of Geographical Sciences, vol. 22, no. 2, pp. 273-282, 2012.

[23] G. Naumann, P. Barbosa, H. Carrao, A. Singleton, and J. Vogt, "Monitoring drought conditions and their uncertainties in Africa using TRMM data," Journal of Applied Meteorology and Climatology, vol. 51, no. 10, pp. 1867-1874, 2012.

[24] A. AghaKouchak and N. Nakhjiri, "A near real-time satellitebased global drought climate data record," Environmental Research Letters, vol. 7, no. 4, Article ID 044037, 2012.

[25] X. C. Ye, Q. Zhang, J. Liu, X. H. Li, and C. Y. Xu, "Distinguishing the relative impacts of climate change and human activities on variation of streamflow in the Poyang lake catchment, China," Journal of Hydrology, vol. 494, pp. 83-95, 2013.

[26] G. Xu and Z. Qin, "Flood estimation methods for Poyang lake area," Journal of Lake Sciences, vol. 10, no. 1, pp. 51-56, 1998 (Chinese).

[27] X. H. Li, Q. Zhang, and C. Y. Xu, "Assessing the performance of satellite-based precipitation products and its dependence on topography over Poyang lake basin," Theoretical and Applied Climatology, 2013.

[28] W. P. Yuan and G. S. Zhou, "Comparison between standardized precipitation index and Z-index in China," Acta Phytoecologica Sinica, vol. 28, no. 4, pp. 523-529, 2004 (Chinese).

[29] H. Wu, M. J. Hayes, A. Weiss, and Q. Hu, "An evolution of the standardized precipitation index, the China- $Z$ index and the statistical Z-score," International Journal of Climatology, vol. 21, no. 6, pp. 745-758, 2001.

[30] R. Daley, Atmospheric Data Analysis, Cambridge University Press, Cambridge, UK, 1991.

[31] J. G. Li, J. R. Li, S. F. Huang, and X. T. Li, "Characteristics of the recent 10-year flood/drought over the Dongting lake basin based on TRMM precipitation data and regional integrated Z-index," Resources Science, vol. 32, no. 6, pp. 1103-1110, 2010 (Chinese). 

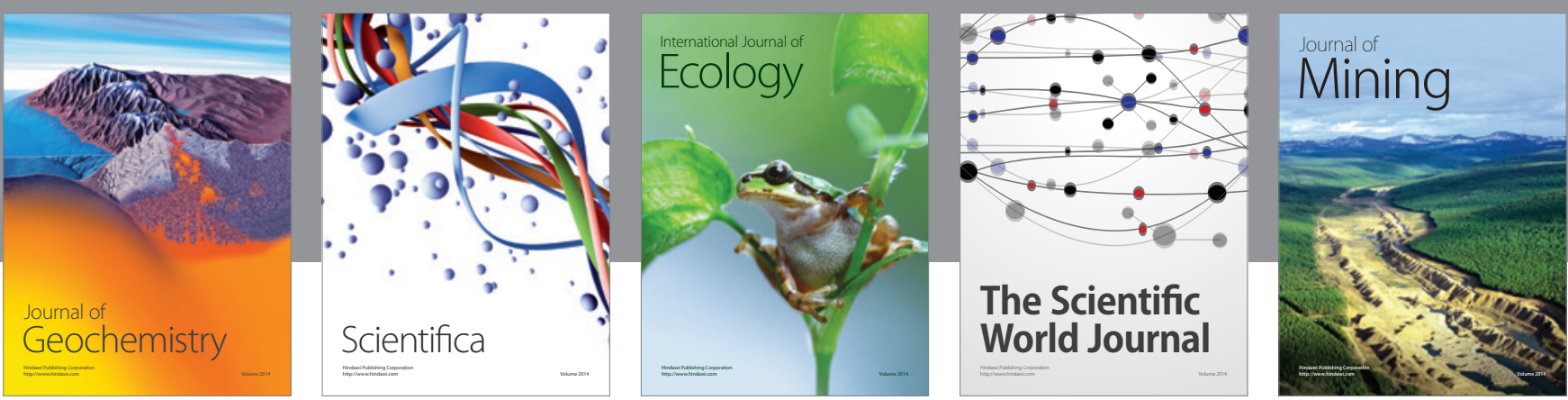

The Scientific World Journal
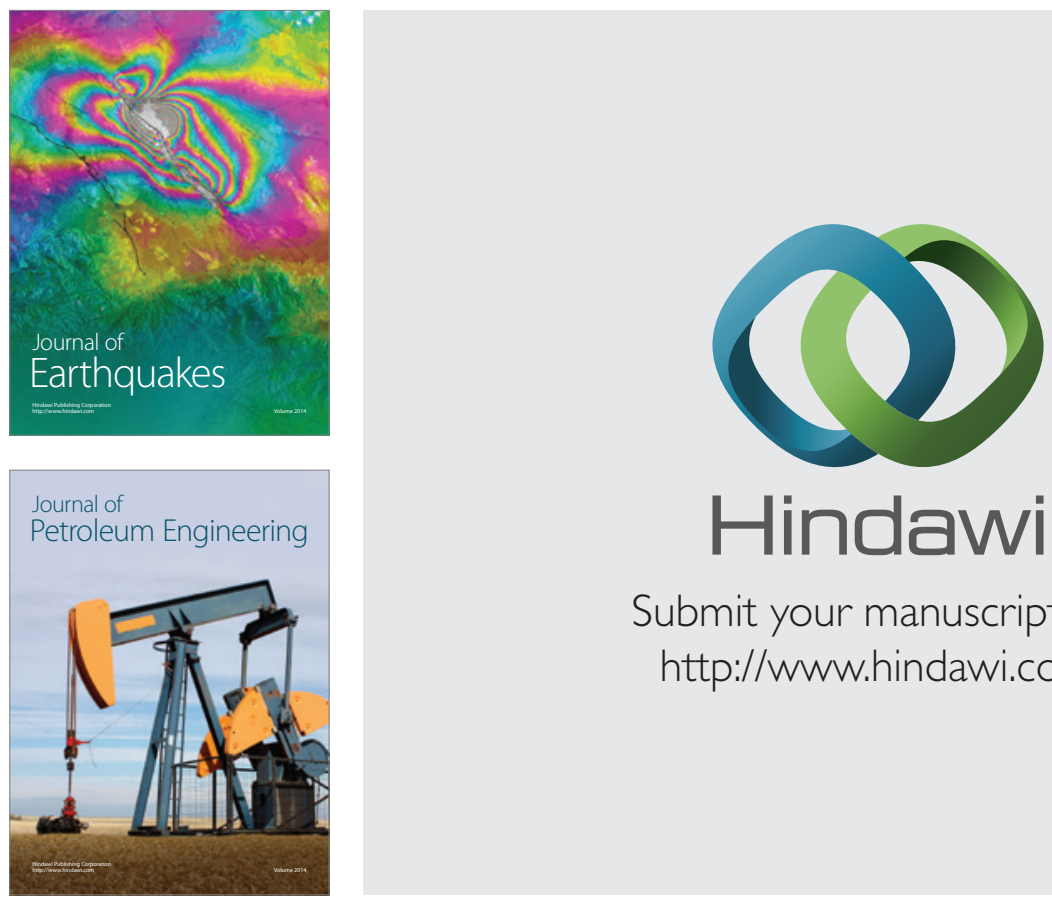

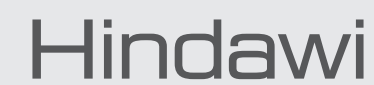

Submit your manuscripts at

http://www.hindawi.com
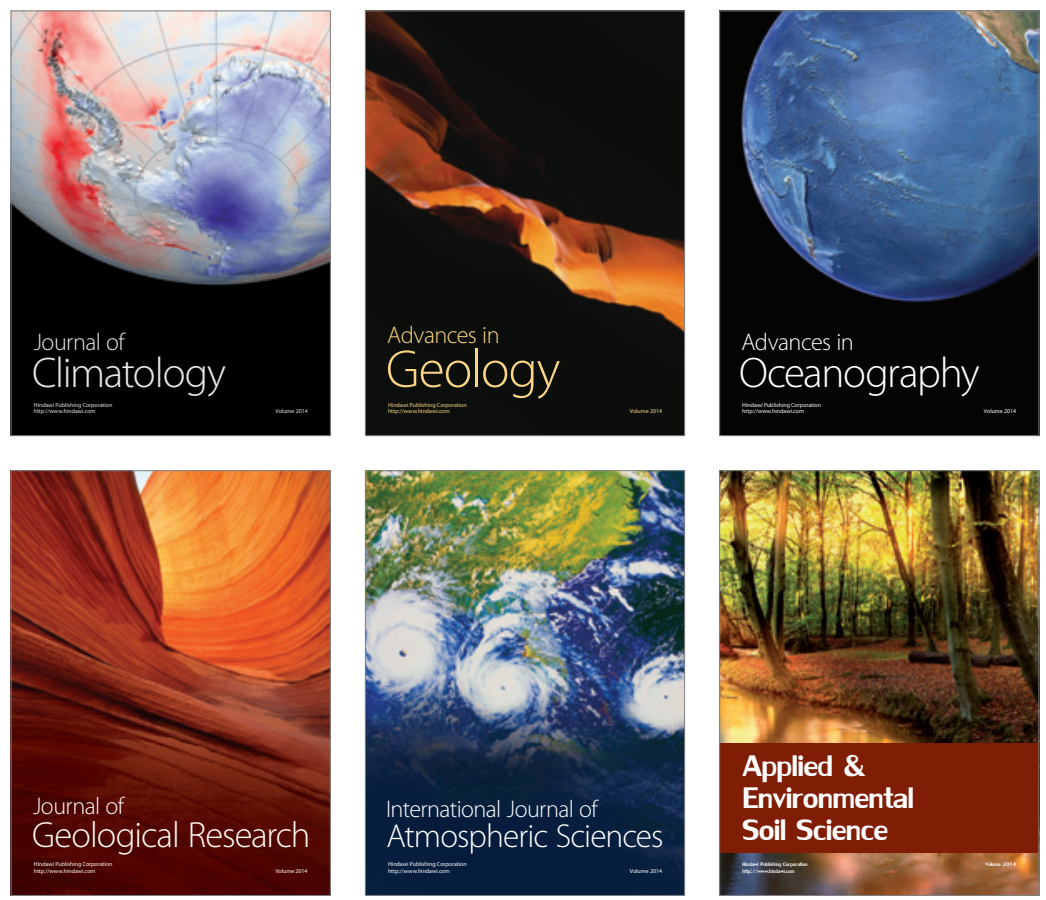
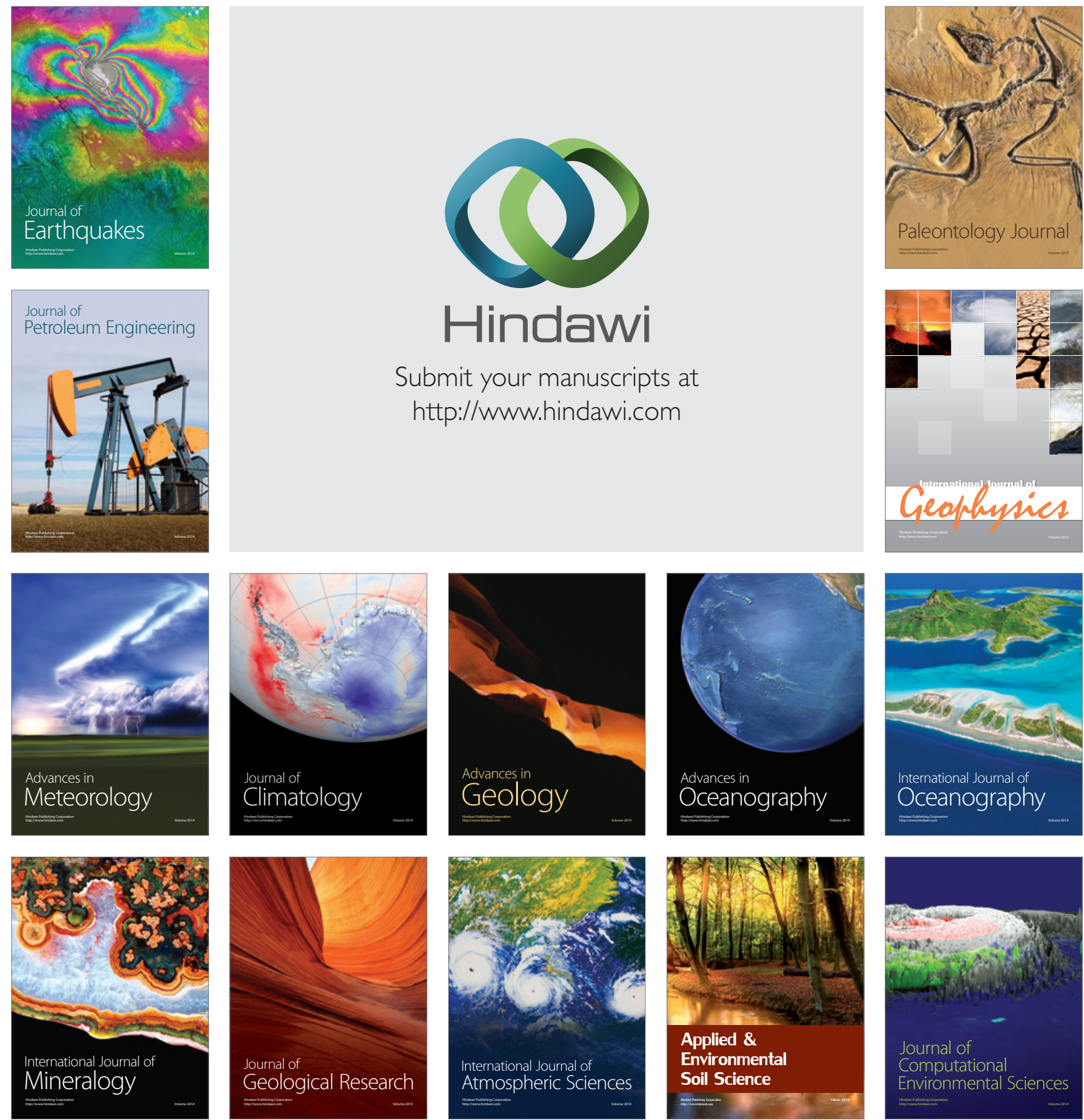